\title{
ESTÁDIOS DE DESENVOLVIMENTO DA CANA-DE-AÇÚCAR E SUAS RELAÇÕES COM A PRODUTIVIDADE
}

\author{
GROWTH STAGES OF SUGARCANE AND ITS EFFECTS ON PRODUCTIVITY
}

\author{
REVISÃO BIBLIOGRÁFICA
}

Maria Isabel da Silva Aude*

\section{RESUMO}

A finalidade principal da cana-de-açúcar é a produção de sacarose, que depende das condições ambientais durante o crescimento e do período de concentração de açúcar. Apresenta quatro estádios de desenvolvimento que são afetados por diversos fatores. A brotação das gemas é afetada pela dominância apical, estado nutricional do tolete, posição da gema no colmo, posição da gema no sulco, tratamento para prevenir doenças, cultivares e fatores climáticos. Logo após a brotação das gemas inicia o perfilhamento que depende principalmente dos fatores climáticos, adubação, cultivares e práticas culturais. Do final do perfilhamento ao início da acumulaçāo de açúcar depende basicamente da idade fisiológica da planta, dos fatores climáticos e nutricionais. Ao completar o ciclo paralisa o crescimento e inicia a concentração de açúcar até atingir valores aceitáveis pela industria. Em temperaturas maiores que $18^{\circ} \mathrm{C}$, a cana poderá continuar no estádio de crescimento até que outro fator determina a paralisação do crescimento e subseqüente acúmulo de açúcar. Deficiência hídrica também paralisa o crescimento e favorece a concentraçāo de açúcar.

Palavras-chave: cana-de-açúcar, estádios de desenvolvimento, produtividade.

\section{SUMMARY}

The main purpose of sugarcane plant is sucrose production that depends of environmental conditions during the growth. There is four growth stages that are affected by divers factors. Bud germination is affected by apical domination, nutrition of stalks pieces for vegetative propagation, bud position ion the culm, bud position on the furrow, treatments to prevent diseases, varieties and climatic factors. After bud germination starts tillering period that depends mainly from climatic factors, fertilization, varieties and cultural practices. From tillering to sugar accumulation begining depends basically from plant physiological age, climatic factors and fertilization. When the sugarcane cycle is completed, paralyse the growth and starts sugar concentration until reach values accepted by industries. In temperatures bigger than $18^{\circ} \mathrm{C}$, the sugarcane will continue the growth until other factor determine growth paralysation and posterior sugar accumulation.

Key words: sugarcane, growth stages, productivity.

\section{INTRODUÇÃO}

A cana-de-açúcar (Saccharum sp.) é uma cultura de grande importância econômica para o Brasil. Diversos estados brasileiros apresentam condições climáticas favoráveis ao seu cultivo. Segundo ALFONSI et al (1987) a cana-de-açúcar é cultivada principalmente entre os paralelos $35^{\circ} \mathrm{LN}$ e $35^{\circ} \mathrm{LS}$, e a duração do período de crescimento vegetativo $e$ bastante variável, sendo de 9 a 10 meses em Luisiana-EUA, até 2 anos ou mais no Perú, África do Sul e Havai. A produtividade média mundial encontra-se em torno de 53t/ha (MAGALHÃES, 1987), enquanto no Brasil a média de três anos foi de 61,5t/ha (ANUÁRIO ESTATíSTICO DO BRASIL, 1988).

A finalidade principal da cana-de-açúcar é a produção de sacarose para a fabricação de açúcar e produção de álcool como fonte alternativa de combustível. A produçāo de sacarose somente será satisfatória, para a indústria, se encontrar condiçōes ambientais favoráveis à concentração de açúcar. Em relação aos

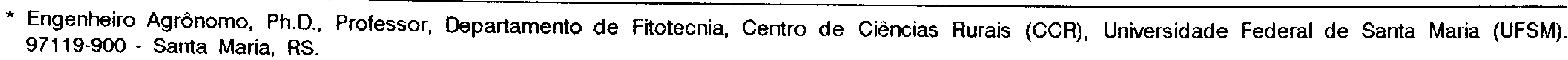


usos MAGALHÃES (1987) relata que além da sacarose, os açúcares redutores contribuem para formar o melaço usado na fabricação de rações e a fibra pode ser utilizada como combustível alternativo na própria indústria (usina).

Os objetivos deste trabalho são descrever os estádios de desenvolvimento da cana-de-açúcar e os fatores de clima, solo, cultivares e práticas culturais que, de certa forma, afetam cada fase do ciclo da cultura.

\section{DESENVOLVIMENTO}

A cana-de-açúcar apresenta quatro estádios de desenvolvimento, segundo Clements apud KRUTMAN (1966), que são os seguintes: do plantio à brotação das gemas, da brotação das gemas ao final do perfilhamento, do final do perfilhamento ao início da acumulação de açúcar e do início da acumulação de açúcar à maturação.

\section{Do plantio a brotação das gemas}

A cana-de-açúcar é propagada por toletes (mudas) com 3-4 gemas, provenientes dos colmos. As gemas são constituídas de células e tecidos em estado de latência e grande poder de diferenciação. A gema apical se situa no ápice da planta e as gemas laterais situamse alternadamente nos nós e são protegidas pelas bainhas das folhas. Para que uma gema brote basta que esteja ligada a uns poucos primórdios ou pontuações radiculares.

A região do nó da planta, onde se encontram as gemas, possui as estruturas necessárias para a obtenção de uma nova planta, como pode ser observado na Fig. 1. Os constituintes do nó são: cicatriz foliar, faixa glauca abaixo da cicatriz foliar, zona radicular ou pontuações radiculares, anel de crescimento acima da zona radicular e gemas

A brotação das gemas ocorre de 3-5 semanas após o plantio e depende de diversos fatores, entre eles a dominância apical, estado nutricional do tolete, posição da gema no colmo, posiçāo da gema no sulco, tratamentos para prevenir doenças, cultivares e fatores climáticos.

\subsection{Dominância apical}

A cana-de-açúcar produz auxinas que se movem do topo para a base da planta, inibindo a brotação das gemas laterais. A dominância apical é importante no plantio da cana-de-açúcar por toletes. Segundo SANTOS (1977), quando se planta colmos inteiros, só germinam as gemas da ponta $e$ as da base, uma vez que estas últimas são menos influenciadas pela dominância apical.

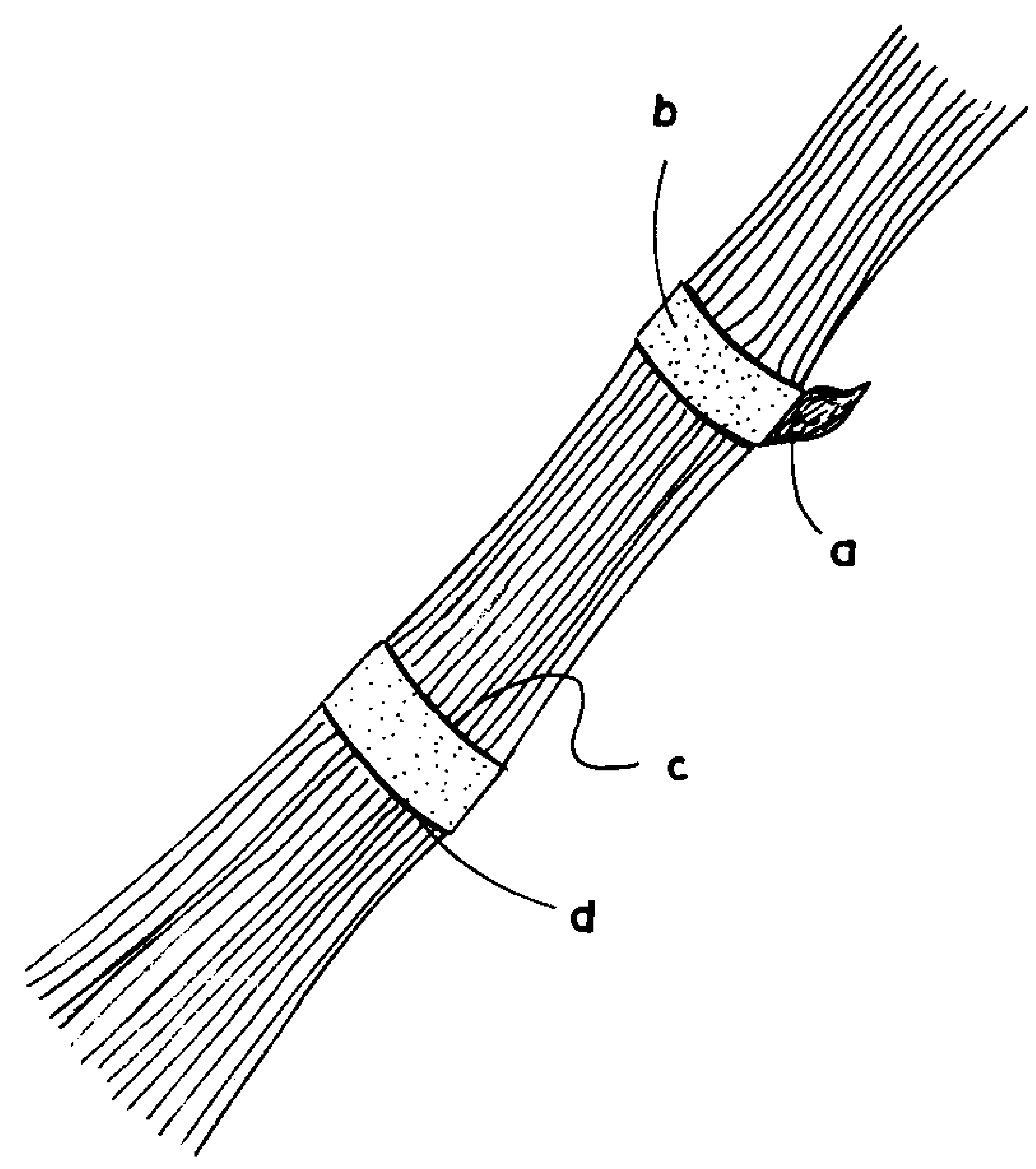

Figura 1 - Brotação de um tolete (muda) de cana-de-açúcar. a) gemas, b) pontuações radiculares, c) anel de crescimento, d) cicatriz foliar, e) zona glauca.

É possivel plantar a cana inteira sem picar em toletes de 3-4 gemas. Neste caso LEE et al (1986) e LEE e SILVA (1987) recomendam usar mudas de canaplanta com 8-10 meses de idade, ou no máximo 12 meses, evitando falhas na germinação. Atualmente já existem produtos químicos que são capazes de quebrar a dominância apical. Dentre os reguladores de crescimento que exercem efeito auxínico encontram-se o ácido indol-acético, ácido naftaleno acético, ácido indolbutírico e 2,4 D (ácido diclorofenoxiacético) (CASAGRANDE, 1991).

\subsection{Estado nutricional do tolete}

Toletes provenientes de canaviais bem nutridos, especialmente com nitrogênio aceleram a brotação das gemas. Arceneaux, apud DILLEWIJN (1952), relata que altas doses de nitrogênio aplicadas na cana-muda aumentaram em $25 \%$ a brotação dos toletes e reduziram o tempo de emergência. A cultura originada de tais toletes apresentou maior produtividade.

AZEREDO e SARRUGE (1984) realizaram o transplante de mudas, provenientes de gemas isoladas, aos 22 dias após o plantio. As mudas ficaram em solução sem alumínio por 26 dias. Após foram adicionados os tratamentos com alumínio, e a colheita foi realizada 35 dias depois. Concluíram que concentrações de 1,56 e 7,49ppm de alumínio, na solução nutritiva, reduziram em $20 \%$ o peso das raízes das cultivares IAC $58-480$ e CB 41-76.

O excesso de sais pode limitar e até inibir a brotação das gemas da cana-de-açúcar (BARNES, 
1964). WEBER e ZAIA (1984) concluíram que houve comportamento diferenciado das cultivares na brotação das gemas, tanto em presença como na ausência das doses de sódio. A presença de até $5,44 \mathrm{meq} / 100 \mathrm{~g}$ de soio não causou decréscimo na brotação das gemas e quanto menor o período de brotação das gemas, menor será o efeito do sal.

\subsection{Posição da gema no colmo}

Os entrenós que se formam por primeiro acumulam açúcar mais cedo e são ricos em sacarose e sais minerais, enquanto os do ápice são ricos em glicose, nitrogênio e água. A brotação das gemas está diretamente correlacionada com o teor de glicose, nitrogênio e água, conseqüentemente a brotação será mais rápida nos toletes provenientes do ápice do colmo. As gemas da base, ricas em sacarose e sais minerais precisam transformar a sacarose em glicose, portanto demoram mais para brotar. Por esta razão, no plantio manual, recomenda-se cruzar a base de um colmo com o ápice do outro, objetivando dar maior uniformidade à lavoura.

\subsection{Posição da gema no sulco}

As gemas se localizam alternadamente no colmo, ficando algumas voltadas para baixo e outras para cima no sulco. As gemas voltadas para baixo demoram mais para emergir, pois precisam circundar o colmo até atingir a superfície do solo. LEE et al (1986) recomendam evitar a cobertura dos toletes com muito solo e que o ideal é cobrir os toletes com $5,0 \mathrm{~cm}$ de solo se a cana for plantada inteira.

\subsection{Efeito dos tratamentos}

O tratamento dos toletes com água quente a $50^{\circ} \mathrm{C}$ por duas horas, para prevenir doenças, estimula a brotação das gemas. Segundo SANTOS (1977), ele elimina toxinas que dificultam a brotação das gemas, facilita a inversão da sacarose em glicose e reduz a dominância apical. Segundo Christoffolet, apud CASAGRANDE (1991), O tratamento a $52^{\circ} \mathrm{C}$ durante 20 a 45 minutos também acelera a brotação, embora a finalidade seja o controle do carvão e insetos que infestam as mudas.

Alguns tratamentos com fungicidas e inseticidas também estimulam a brotação das gemas. Certos compostos não saturados, como a cloridrina, o acetileno e possivelmente 0 etileno baixam 0 nivel de auxinas naturais, favorecendo a brotação.

\subsection{Cultivares}

Existe diferença varietal na velocidade de brotação das gemas. Nas cultivares precoces a brotação é mais rápida do que nas tardias. Segundo MALAVOLTA e HAAG (1964), em algumas cultivares as raízes se desenvolvem antes do que a parte aérea, noutras a situação é inversa, e ainda existem cultivares onde ambas as partes se desenvolvem simultaneamente. BROADHEAD (1970) concluiu que em condiçōes adversas de crescimento, a cultivar CP 36-111 germinou mais lentamente do que a CP 52-48 e CP 67-500. Outro fator importante e a presença de baínha nas folhas de algumas cultivares. Exerce efeito desfavorável à brotação das gemas, funcionando omo um obstáculo mecânico ao contato da gema com a umidade do solo.

\subsection{Fatores climáticos}

O excesso de umidade produz fermentação dos toletes, prejudicando a brotação das gemas enquanto uma severa deficiência hídrica poderá provocar a mumificação das gemas (desidratação), impedindo a brotação. Segundo MALAVOLTA e HAAG (1964) a brotação das gemas é acelerada quando se deixa os toletes perderem previamente parte da umidade.

A temperatura no estádio de brotação das gemas afeta o número de colmos, o crescimento e a produção final de colmos industrializáveis. GASCHO et al (1973) relatam que todas estas variáveis apresentam maiores valores quando a temperatura se encontra ao redor de $30^{\circ} \mathrm{C}$, enquanto temperaturas menores do que $20^{\circ} \mathrm{C}$ e maiores que $35^{\circ} \mathrm{C}$, resultam em valores menores. SANTOS (1977) cita que temperaturas do solo abaixo de $10^{\circ} \mathrm{C}$ são prejudiciais, afetando drasticamente a brotação das gemas, que encontra o ponto ótimo em torno de $32^{\circ} \mathrm{C}$, sendo $21^{\circ} \mathrm{C}$ a temperatura base para este estádio. Segundo Clements e Nakata, apud GAS$\mathrm{CHO}$ et al (1973), a temperatura mínima para a emergência da cana-de-açúcar está ao redor de $12^{\circ} \mathrm{C}$.

Outros fatores que afetam a brotação das gemas são: intervalo de tempo entre o corte da muda e a distribuição no sulco de plantio, e entre a distribuição da muda no sulco e a cobertura com solo, tempo que os sulcos ficam abertos, número de gemas e idade dos toletes.

\section{Da brotação das gemas ao final do perfilhamento}

Após a brotação da gema se desenvolvem os rizomas que são semelhantes ao colmo aéreo, porém os entrenós são mais curtos, grossos e escuros. Possuem todas as estruturas do colmo e os primeiros que surgem são chamados de primários, originando colmos secundários, que por sua vez produzirāo terciários, formando a touceira (Fig. 2). SAMPAIO et al (1987) relatam que dos $6,5 \mathrm{t} / \mathrm{ha}$ de sistema radicular, $3,7 \mathrm{t} / \mathrm{ha}$ correspondiam aos colmos subterrâneos.

O perfilhamento deve iniciar de forma intensa para que todos os perfilhos se desenvolvam com a 


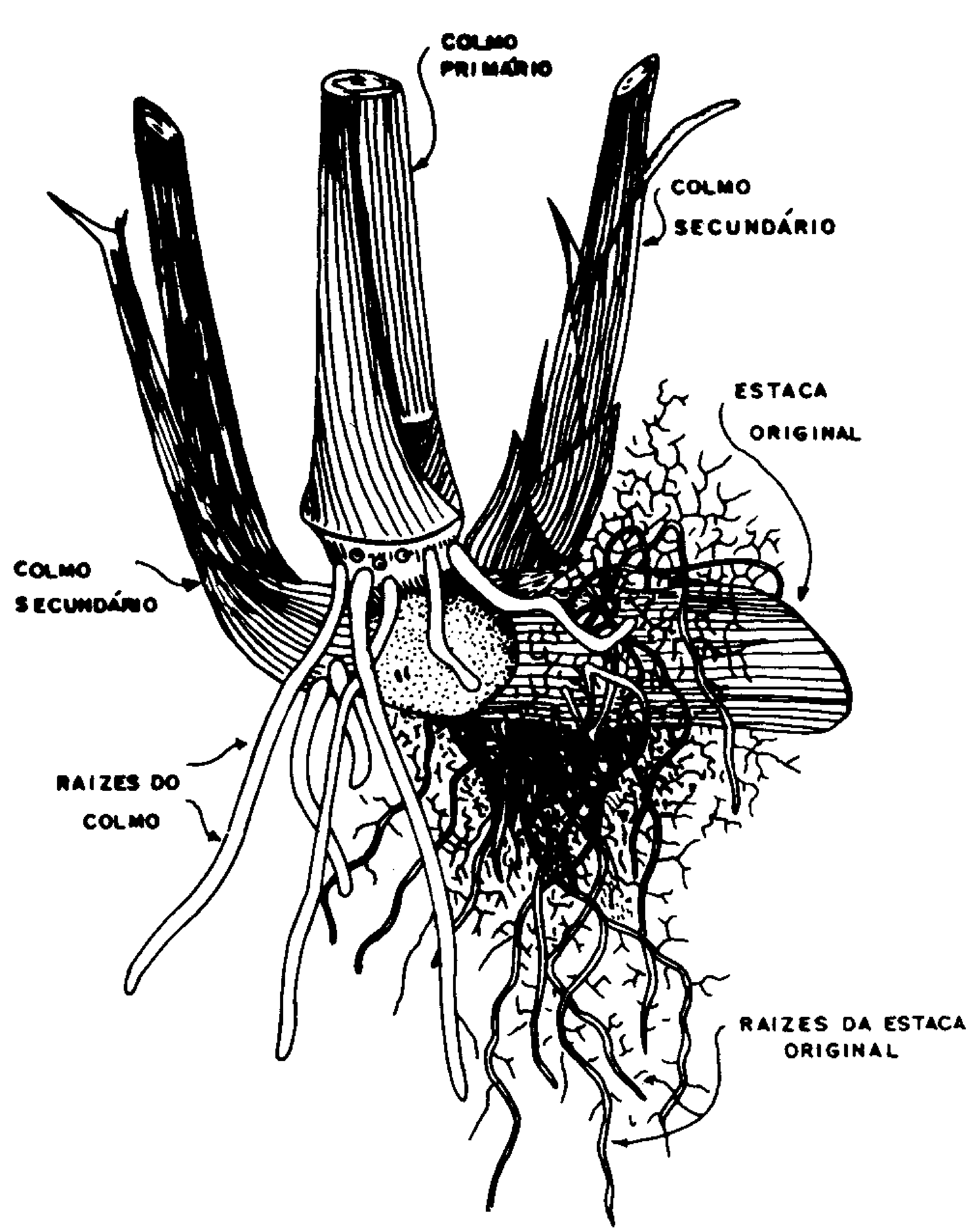

Figura 2 - Principais constituintes que se desenvolvem do tolete da cana-de-açúcar, durante o perfiIhamento.

Fonte: MALAVOLTA e HAAG (1964)

mesma idade. Em trabalho citado por CASAGRANDE (1991), o máximo de perfilhamento ocorreu aos quatro meses após o plantio. $O$ estádio de perfilhamento é afetado por diversos fatores, entre eles os climáticos, adubaçāo, cultivares e práticas culturais.

\subsection{Fatores de clima}

A deficiência hídrica diminui e até impede 0 perfilhamento da cana-de-açúcar. Em regiōes onde ocorre deficiência hídrica, recomenda-se irrigaçāo para aumentar o número de perfilhos. Em solos com excesso de umidade o perfilhamento é menor.

$O$ efeito da radiação solar tem a ver com produção de auxinas, no ápice da planta (MALAVOLTA e HAAG, 1964). Em presença de radiação solar adequada diminui o transporte das auxinas para a base do colmo, quebrando a inibição das gemas, que produzem novos colmos. Quanto maior a radiação solar, maior será o número de perfilhos. Canas que se desenvolvem a sombra não perfilham ou têm perfilhamento reduzido. Segundo MAGALHÃES (1987) o auto-sombreamento induz inibiçāo do perfilhamento e acelera o crescimento do colmo principal. Este crescimento em altura continua até a ocorrência de algum fator limitante, como deficiência hídrica, temperaturas baixas ou florescimento. $O$ número de horas de luz solar, conseqüentemente afeta o perfilhamento, sendo este menos intenso em dias curtos do que dias longos (SANTOS, 1977).

O perfilhamento aumenta à medida que a temperatura se eleva até ao redor de $30^{\circ} \mathrm{C}$.

\subsection{Efeito do nitrogênio}

Adubação com nitrogênio favorece o perfilhamento. Toletes provenientes de canaviais bem nutridos produzem maior número de perfilhos. SANTOS (1977) relata que cana-mudas de diferentes cultivares foram testadas com três níveis de $\mathrm{N}$ e dois de radiaçāo solar. Aos oito meses de idade foram cortados em três gemas para o plantio. Foi observado que no pré-tratamento $100 \%$ de luz sem $N$ produziu 70 perfilhos e quando foram aplicados $90 \mathrm{~kg} /$ ha de $N$, o número de perfilhos mais do que dobrou.

\subsection{Cultivares}

O número de perfilhos varia com as cultivares, sendo uma característica que serve para diferenciá-las (ARANHA e YAHN, 1987). Algumas chegam a produzir 29 perfilhos, como a IAC 50-132 (MALAVOLTA e HAAG, 1964). Todos os perfilhos sāo capazes de produzir colmos industrializáveis, desde que outros fatores não sejam limitantes.

\subsection{Práticas culturais}

Espaçamentos menores produzem número de perfilhos reduzido pois há muita competição entre plantas por água, luz e nutrientes. Isto está bem explicado no trabalho de MACHADO et al (1982). Houve superproduçăo de colmos nos estádios iniciais das cultivares NA 56-79 e CB 41-14, com um máximo ao redor de 125 dias após o plantio, seguido de acentuado declínio, estabilizando-se por volta de 250 dias após o plantio, com 9 e $8 \mathrm{colmos} / \mathrm{m}^{2}$, respectivamente. Houve uma redução natural de $50 \%$ no número de colmos $/ \mathrm{m}^{2}$, em função da competição entre colmos e do progressivo sombreamento exercido pelas plantas mais desenvolvidas.

Toletes cobertos com menor quantidade de so10, por ocasião do plantio, produzem maior número de perfilhos. Por esta razão, recomenda-se cobrir os toletes com $5-10 \mathrm{~cm}$ de solo, dependendo de ser argiloso ou arenoso.

A poda é uma prática que consiste na retirada da gema apical, não recomendada em condições normais de cultivo. No entanto a ocorrência de geadas, pragas e doenças, que destruam a gema apical, promovem o perfilhamento pela quebra da dominância apical. Em canas jovens, o ataque da broca (Diatraea sacchara- 
lis) provoca morte do colmo principal, favorecendo maior perfilhamento (SANTOS, 1977).

Em relação ao uso de bio-reguladores LUCHESI et al (1979) relatam que não houve efeito do ácido 2-cloroetil fosfônico na indução do perfilhamento, quando a aplicação foi realizada na cana-planta. No entanto, em cana-soca ocorreu aumento no número de colmos industrializáveis e que o estádio indicado para a aplicação do produto é logo após o aparecimento dos primeiros brotos das socas.

\section{Do final do perfilhamento ao início da acumulaçăo de açúcar}

Após todos os perfilhos estarem formados inicia - estádio de crescimento da cana-de-açúcar. Este estádio se caracteriza por intensa divisão, diferenciação e alongamento celular. Como conseqüência ocorre aumento no tamanho e na matéria seca total da planta. É conhecido como o "grande período de crescimento" da cana-de-açúcar. No início é lento, depois cresce rapidamente até atingir um máximo, e, em seguida há uma diminuição na quantidade de matéria seca produzida (MALAVOLTA e HAAG, 1964; SANTOS, 1977; MACHADO, 1987).

Os entrenós jovens, que se formam primeiro, contém grande quantidade de açúcares redutores como glicose e frutose, enquanto os maduros quase não os contém (GLASZIOU, 1960). A idade fisiológica da planta e o clima são fatores que afetam estas relações.

\subsection{Fatores de clima}

A cana-de-açúcar é uma planta $\mathrm{C} 4$, possuindo grande eficiência fotossintética e elevado ponto de saturação luminosa. Quanto maior a radiação solar, mais fotossíntese será realizada, conseqüentemente maior será - crescimento e o acúmulo de açúcar. Em presença de maior radiação solar os colmos são mais grossos e curtos e as folhas mais largas e verdes, apresentando elevada produtividade. Em luz deficiente ou com redução de 15 a $20 \%$ na radiação solar (SANTOS, 1977) os colmos tornam-se mais finos e longos, as folhas estreitas verde-amareladas $e$ as plantas mais suculentas, apresentando menos matéria seca em detrimento da produção.

A fotossíntese em cana-de-açúcar eleva-se linearmente com 0 aumento da irradiância, entre 0,2 a $0,6 \mathrm{cal} \cdot \mathrm{cm}^{-2} \cdot \mathrm{min}^{-1}$, ocorrendo saturação acima de 0,9 cal. $\mathrm{cm}^{-2} \cdot \mathrm{min}^{-1}$ (WALDRON et al, 1967).

A translocação da sacarose é menor durante a noite (KORTSCHAK e HARTT, 1967). A sacarose translocada durante o dia é obtida pela fotossíntese, enquanto que a translocada à noite é obtida pela conversão de outros compostos (ácidos orgânicos, fosfato orgânico e resíduos insolúveis). Segundo Barbieri apud CASAGRANDE (1991), em geral o comprimento do colmo aumenta com o comprimento do dia variando de 10 a 14 horas, sendo porem, reduzido por fotoperíodos longos entre 16 e 18 horas.

O consumo de água pela cana-de-açúcar varia com o estádio vegetativo que a cultura se encontra e a cultivar utilizada (ALFONSI et al, 1987), sendo portanto, função da área foliar, estádio fisiológico e densidade do sistema radicular.

Em solos no ponto de murcha ou solos mal drenados ocorre a paralização do crescimento, reduzindo drasticamente a atividade fotossintética, em detrimento da produtividade. Segundo HARTT (1967) a translocação de fotossintatos é menor em plantas com deficiência hídrica.

Ventos constantes diminuem o desenvolvimento da parte aérea e aumentam o sistema radicular. 0 crescimento das raízes é lento inicialmente, quando as raízes dos toletes ainda estão ativas. Com o estabelecimento da planta, a velocidade de crescimento das raízes aumenta para depois declinar (SANTOS, 1977). Ventos frios provocam estrias ou faixas cloróticas nas foIhas, reduzindo a área foliar.

A temperatura base da cana-de-açúcar está em torno de $19-20^{\circ} \mathrm{C}$. Abaixo destas temperaturas não há crescimento vegetativo. Segundo Fauconier e Basserau, apud ALFONSI et al (1987), em temperatura abaixo de $25^{\circ} \mathrm{C}$ o crescimento da cana é lento, entre 30 e $34^{\circ} \mathrm{C}$ é máximo e que acima de $35^{\circ} \mathrm{C}$ torna-se também lento, sendo praticamente nulo em temperaturas superior a $38^{\circ} \mathrm{C}$. Observa-se que a cana-de-açúcar é praticamente tolerante a altas temperaturas. No entanto, MAGALHÃES (1987) relata que pode haver alta produtividade em temperaturas ao redor de $47^{\circ} \mathrm{C}$, desde que seja empregada irrigação. Temperaturas menores que $21^{\circ} \mathrm{C}$ diminuem a taxa de alongamento dos colmos e promovem acumulação de sacarose. Segundo SANTOS (1977), quando a temperatura do ar cair abaixo de $8^{\circ} \mathrm{C}$ ou se elevar acima de $32,5^{\circ} \mathrm{C}$, aparecem estrias ou faixas cloróticas nas folhas, devido a redução da síntese da clorofila.

\subsection{Efeito dos nutrientes}

A translocação dos fotossintatos das folhas para o colmo decresce com a deficiência de nitrogêniu, reduzindo o crescimento. HARTT (1970a) relata que a deficiência de nitrogênio diminuiu a percentagem de $\mathrm{N}$ e clorofila nas folhas da cana-de-açúcar. A translocação do ${ }^{14} \mathrm{C}$ foi menor com a deficiência de nitrogênio.

A deficiência de potássio diminui a acumulação de sacarose e os colmos apresentam-se ricos em açúcares redutores. Em trabalho realizado por HARTT (1970b) uma severa deficiência de potássio decresceu a translocação do ${ }^{14} \mathrm{C}$, tanto em presença como em ausência de luz.

Inúmeros bio-reguladores têm sido testados pa- 
ra cana-de-açúcar no Havai, Filipinas, Austrália, Estados Unidos e Porto Rico. $O$ ácido giberélico aumenta 0 comprimento dos entrenós e prolonga o período de atividade fotossintética, conseqüentemente aumenta a produtividade. Em trabalho realizado por CASTRO et al (1982), a aplicação do ácido giberélico nas doses de 60,100 e $150 \mathrm{~g} / \mathrm{ha}$ aumentou o crescimento da cana-deaçúcar. Quando a aplicação foi feita aos 112 dias antes da colheita, aumentou a produção. LUCCHESI et al (1980) relatam que a utilizaçāo do ácido 2-cloroetil fosfônico aumentou o número de colmos.

\section{Do início da acumulação de açúcar à maturação}

A cana-de-açúcar ao completar o ciclo diminui a assimilação (produção de glicose e frutose), paralisa 0 crescimento e inicia a concentração de açúcar até atingir valores aceitáveis pela indústria. As folhas tornam-se amareladas, as inferiores secam e os colmos adquirem a coloração característica da cultivar.

0 amadurecimento ou acumulação de sacarose é um processo que se realiza entrenó por entreno. 0 entrenó que se forma primeiro acumula açúcar antes que os demais. Nas plantas jovens o conteúdo de sacarose apresenta-se máximo ao nível do solo, decrescendo rapidamente no sentido da base para a ponta do colmo. Quando a planta cresce, o teor de sacarose aumenta gradativamente nos entrenós mais velhos até atingir estado de maturação, quando estabiliza a concentração de sacarose (SANTOS, 1977).

$\mathrm{Na}$ época da colheita os colmos industrializáveis devem apresentar no mínimo $18^{\circ}$ Brix (teor de sólidos solúveis no caldo), polarização mínima de $15,3 \%$ (percentagem de sacarose aparente no caldo), pureza mínima de $85,0 \%$ (percentagem de sacarose aparente no caldo em sólidos solúveis) e no máximo $1,0 \%$ de açúcares redutores, como glicose e frutose. Um canavial que apresentar estas condiçōes terá um rendimento em torno de $11,3 \%$ de açúcar. A maturação e influenciada por fatores de clima, solo, cultivares e estado sanitário do canavial.

\subsection{Clima}

Em todas as partes do mundo onde se cultiva cana-de-açúcar, a maturação é drasticamente influenciada pelas condiçōes climáticas. A temperatura deve estar abaixo de $18^{\circ} \mathrm{C}$ para que a cana paralise o crescimento $\theta$ inicie a acumulação de açúcar. Em temperaturas maiores, poderá continuar no estádio de crescimento até que outro fator determine a paralisação do crescimento e subseqüente acúmulo de açúcar. A deficiência hídrica também paralisa o crescimento, favorecendo a concentração de sacarose e diminuição dos açúcares redutores. O excesso de umidade no estádio de maturação diminui 0 teor de açúcar produzindo sérios danos para a indústria.

No Havaí, cujo clima e tropical, quente e úmido, com chuvas bem distribuídas durante 0 ano, os produtores utilizam irrigação em todos canaviais (GRANER \& GODOY, 1967). Dois a três meses antes da coIheita, a irrigação é suspensa e com este estresse a planta pára de crescer e acumula açúcar. Desta forma, a colheita é realizada durante todo 0 ano. No Nordeste brasileiro, a cana-de-açúcar é plantada em época tal que a maturação coincida com o período de maior deficiência hídrica (setembro a abril). No Rio Grande do Sul, a partir de abril-maio a temperatura começa a declinar, o que favorece a concentração de açúcar.

\subsection{Solo}

Em solos argilosos, que retêm maior quantidade de água, ocorre atraso na maturação, visto que a cana-de-açúcar permanece no estádio de crescimento intenso por um período maior de tempo. Ao contrário, se o solo for arenoso, acelera a maturação. Dentro deste princípio, adubações com nitrogênio, feitas tardiamente retardam a maturação.

\subsection{Cultivares}

As cultivares de cana-de-açúcar se classificam em precoces, médias e tardias em relação a época que acumulam açúcar, tendo portanto, seus períodos de maturação diferenciados. Cultivares de ciclo precoce acumulam açúcar mais cedo e estão prontas para ser coIhidas no início da safra, enquanto as tardias somente poderão serem colhidas no final da safra. Além disto, se classificam em função do período útil de industrialização (PUI), que é o período desde o momento que a cana-de-açúcar alcançou grau Brix desejável pela indústria, até a colheita, sem ocorrer inversão da sacarose. Cultivares precoces de PUl curto devem ser colhidas logo que alcançarem $18^{\circ}$ Brix, caso contrário iniciará a inversão da sacarose em moléculas de glicose, diminuindo a concentração de açúcar. Segundo STUPIELLO (1987) entre as cultivares de PUI longo (mais de 150 dias) encontram-se a NA 56-79, SP 71-799, SP 70-1284 e SP 71-6163 que podem ser industrializadas em 2/3 da safra. As cultivares IAC 52-150, CB 41-76, CB 47-355 e CP 51-22 apresentam PUI curto (70-100 dias), limitando a industrialização a um período reduzido da safra. As cultivares de ciclo médio são SP. 70-1143 e SP 71-1406 com PUI de 120-150 dias.

\subsection{Estado sanitário}

As plantas de cana-de-açúcar atacadas por doenças tendem acumular açúcar mais cedo pois paralisam em parte o crescimento, ocorrendo mais cedo a maturação dos canaviais doentes e debilitados. A podri- 
dão vermelha do colmo age inversamente (SANTOS, 1977) retardando ou impedindo a maturação.

\subsection{Amadurecedores químicos}

Atualmente tem-se utilizado produtos químicos que reduzem o crescimento da cana-de-açúcar, acelerando a maturação. Atuam inibindo a multiplicação celular da região de crescimento e a formação de novas partes vegetativas como folhas, entrenos e a própria inflorescência. No entanto, segundo FERNANDES (1977) a planta não interromperá a absorção de nutrientes e a produção de açúcares. Conseqüentemente, maior quantidade de açúcar será transformada em sacarose nos entrenós.

O produto químico como fator de amadurecimento, compensa os outros fatores favoráveis ao amadurecimento. Deverá ser aplicado na fase de maior absorção radicular e de pleno desenvolvimento vegetativo (FERNANDES, 1977).

\section{CONCLUSÕES}

- A cana-de-açúcar apresenta quatro estádios de desenvolvimento. A brotação das gemas é afetada pela dominância apical, estado nutricional do tolete, posição da gema no colmo, posição da gema no sulco, tratamento para prevenir doenças, cultivares $\theta$ fatores climáticos.

- O perfilhamento depende de fatores climáticos, adubação, cultivares e práticas culturais e o crescimento é função da idade fisiológica da planta, fatores climáticos e nutricionais.

- Para que a cana paralise o crescimento e inicie a acumulação de sacarose é necessário que a temperatura esteja abaixo de $18^{\circ} \mathrm{C}$ ou que ocorra deficiência hídrica.

\section{REFERÊNCIAS BIBLOGRÁFICAS}

ANUÁRIO ESTATÍSTICO DO BRASIL. Rio de Janeiro: IBGE, 1988, v. 48, p. 334-335.

ALFONSI, R.R., PEDRO JUNIOR, M.J., BRUNINI, O. et al. Condições climáticas para a cana-de-açúcar. In: PARANHOS, S.B. Cana-de-açúcar: Cultivo e utilização. Campinas: Fundação Cargill, 1987. v. 1, cap. 1, p. 42-55.

ARANHA, C., YAHN, C.A. Botânica da cana-de-açúcar. In: PARANHOS, S.B. Cana-do-açúcar: Cultivo e utilização. Campinas: Fundação Cargill, 1987. v. 1, cap. 1, p. 3-18.
AZEREDO, D.F., SARRUGE, J.R. Alumínio na produção de matéria seca em diferentes cultivares de cana-deaçúcar (Saccharum spp). Saccharum São Paulo, v. 7, n. 34, p. 17-23, 1984.

BARNES, A.C. The sugar cane. London: Hill Ed., 1964. $456 \mathrm{p}$.

BROADHEAD, D.M. Germination of stored sugarcane cuttings. Agron J, Madison, v. 62, n. 6, p. 831-832, 1970.

CASAGRANDE, A.A. Topicos de morfologia $\theta$ fisiologia da cana-de-açúcar. Jaboticabal: FUNEP, 1991. $157 \mathrm{p}$.

CASTRO, P.R.C., DIONISIO, A., JOÄO, J. et al. Aumento da produção de cana-de-açúcar com ácido giberélico. Brasil Açucareiro Rio de Janeiro, v. 99, n. 3, p. 35-42, 1982.

DILLEWIJN, C. Van. Botany of sugarcane Waltham, Mass.: The Chronica Botanica Co., 1952. 371 p.

FERNANDES, J. Fatores de amadurecimento da canade-açúcar. Brasil Açucareira Rio de Janeiro, v. 90, n. 3, p. 116-121, 1977.

GASCHO, G.J., RUELKE, O.C., WEST, S.H. Residual effects of germination temperature in sugarcane. Crop Sci, Madison, v. 13, n. 2, p. 274-279, 1973.

GLASZIOU, K.T. Accumulation and transformation of sugars in sugarcane stalks. Plant Physiology, Baltimore, v. 35, n. 6, p. 895-901, 1960.

GRANER, E.A., GODOY JR., C. Culturas da fazenda brasileira 4. ed. São Paulo: Melhoramentos, 1967. $461 \mathrm{p}$.

HARTT, C.E. Effect of moisture supply upon translocation and storage of ${ }^{14} \mathrm{C}$ in sugarcane. Plant Physiology, Baltimore, v. 42, n. 3, p. 338-346, 1967.

HART, C.E. Effect of nitrogen deficiency upon translocation of ${ }^{14} \mathrm{C}$ in sugarcane. Plant Physiology, Baltimore, v. 46, n. 3, p. 419-422, 1970 a.

HARTT, C.E. Effect of potassium deficiency upon translocation of ${ }^{14} \mathrm{C}$ in detached blades of sugarcane. Plant Physiology, Baltimore, v. 45, n. 2, p. 183-187, 1970b.

KORTSCHAK, H.P., HARTT, C.E. Translocation of ${ }^{14} \mathrm{C}$ in the sugarcane plant during the day and night. Plant Physiology, Baltimore, v. 42, n. 1, p. 89-94, 1967.

KRUTMAN, S. Do Grande período de variedades de cana. Pesquisa Agropecuária Brasileira. Brasília, v. 11, p. 395-400, 1966.

LEE, T.S.G., MARTINS, J., MATSUOKA, S. et al. Plantio da cana inteira-viabilidade e recomendaçōes. Saccharum, São Paulo, v. 9, n. 43, p. 20-23, 1986.

LEE, T.S.G., SILVA, M.R. da. Pré-tratamento de mudas para o plantio da cana inteira. Brasil Açucareiro, Rio de Janeiro, v. 105, n. 5/6, p. 36-40, 1987.

LUCCHESI, A.A., FLORENCIO, A.C., GODOY, O.P. et al. Influência do ácido 2-cloroetil fosfônico na induçăo do perfilhamento em cana-de-açúcar (Saccharum spp.)variedade NA 56-79. Brasil Açucareira Rio de Janeiro, v. 93, n. 4 , p. 19-26, 1979. 
LUCCHESI, A.A., GODOY, O.P. FLORENCIO, A.C. et al. Efeito do ácido 2-cloroetil fosfônico e de sua mistura com uréia, na indução do perfilhamento em soqueira de cana-de-açúcar. (Saccharum Spp), variedade CB 41-14. Brasil Açucareira Rio de Janeiro, v. 95, n. 4, p. $54-58,1980$.

MACHADO, E.C. Fisiologia da produção de cana-de-açúcar. In: PARANHOS, S.B. Cana-de-açúcar: Cultivo e utilização. Campinas: Fundação Cargill, 1987. v. 1, cap. 1, p. 56-87.

MACHADO, E.C., PEREIRA, A.R., FAHL, J.I. et al. Índices biométricos de duas variedades de cana-de-açúcar. Pesq Agropec Bras, Brasília, v. 17, n. 9, p. 1323-1329, 1982.

MAGALHÃES, A.C.N. Ecofisiologia da cana-de-açúcar: aspectos do metabolismo do carbono na planta. In: CASTRO, P.R.C., FERREIRA, S. O., YAMADA, T. Ecofiologia da produção agrícola Piracicaba: Assoc. Bras. da Potassa e do Fosfato. 1987. p. 113-118.

MALAVOLTA, E., HAAG, H.P. Fisiologia. In: MALAVOLTA, E., SEGALA, A.L., GOMES, F.P., et al. Cultivo $\theta$ adubação da cana-de-açúcar. Campinas: Instituto Brasileiro de Potassa, 1964. cap. 8, p. 221-236.
SAMPAIO, E.V.S.B., SALCEDO, I.H., CAVALCANTI, F.J.A. Dinâmica de nutrientes em cana-de-açúcar. Ill. Conteúdo de nutrientes e distribuição radicular no solo. Pesq Agropec Bras, Brasília, v. 22, n. 4, p. 425-431, 1987.

SANTOS, D. dos. Ecofisiologia da cana-de-açúcar. In: Recomendaçōes técnicas para cultura da cana-de-açúcar no estado do Paraná Londrina: Instituto Agronômico, 1977, 107 p. (Circular IAPAR, 6).

STUPIELLO, J.P. A cana-de-açúcar como matéria-prima. In: PARANHOS, S.B., Cana-de-açúcar: Cultivo e Utilização. Campinas: Fundação Cargill, 1987. v. 2, cap. 7. p. 759-804.

WALDRON, J.C., GLASZIOU, K.T., BULL, T.A. The physiology of sugarcane. IX. Factors affecting phothosynthesis and sugar storage. Australian Journal od Biological Sciences Melbourne, v. 20, n. 6, p. 1043-1052. 1967.

WEBER, H., ZAIA, A.O. Efeito da salinidade na germinação, no crescimento inicial e na concentração de nutrientes em cultivares de cana-de-açúcar (Saccharum spp). Saccharum São Paulo, v. 7 , n. 34, p. 26-33, 1984. 